\title{
Alargamiento de los gastrocnemios y transposiciones tendinosas del tibial anterior y el extensor largo del primer dedo en un paciente con neuropatía del nervio peroneo común. Caso clínico
}

Elongation of the gastrocnemius and tendon transfer of anterior tibial and long extensor of the first finger in a patient with common peroneal nerve neuropathy. Case report Joaquín Óscar Izquierdo Cases ${ }^{a}$, Irene Izquierdo Santiago y y Julián García Carrascob

${ }^{a}$ Centro Clínico Quirúrgico. Aranjuez. ${ }^{b}$ Clínica del Pie Romea. Murcia. España

Palabras clave:

Trasferencia tendinosa, tibial anterior, tenosuspensión de Jones, artrodesis interfalángica, gastrocnemios, neuropatía del nervio peroneo común, equino, equino funcional, cirugía podológica.

\section{Resumen}

Presentamos el caso de un paciente de 52 años con deformidad en equino secundaria a una parálisis flácida, debido a una poliomielitis que sufrió en la infancia. En la exploración física se observa limitación de la flexión dorsal activa de tobillo, primer radio en plantarflexión y un primer dedo en garra rígida. La deformidad en equino era reductible. En el análisis de la marcha se aprecia una limitación en la flexión dorsal de tobillo en la fase de contacto inicial, con contacto de antepié y un aumento de la flexión de rodilla y cadera en la fase de oscilación. Previamente había sido intervenido de un alargamiento del extensor largo del primer dedo. Se realizó una transferencia del músculo tibial anterior (TA) a la tercera cuña, una tenosuspensión de jones junto con una artrodesis de la articulación interfalángica del primer dedo. También se realizó un alargamiento de los gastrocnemios. Doce meses después de la cirugía el rango de movimiento activo de tobillo era de $35^{\circ}$ en flexión plantar y $0^{\circ}$ en flexión dorsal, y un rango de movimiento pasivo de dorsiflexión de $15^{\circ}$ y plantarflexión de $60^{\circ}$. Se corrigió la deformidad en equino, ganando además una ligera dorsiflexión activa de tobillo. La transferencia tendinosa combinada del tibial anterior y del extensor largo del primer dedo con alargamiento de los gastrocnemios como tratamiento de rescate de la deformidad en equino flácido por una neuropatía del nervio peroneo común es un tratamiento a tener en cuenta para la corrección de dicha deformidad.
Keywords:

Tendon transfer, anterior tibial tendon, Jones tenosuspension, interphalangeal arthrodesis, gatrocnemius, common peroneal neuropathy, equine, functional equine, podiatric surgery.

\begin{abstract}
We present the case of a 52-year-old patient with an equine deformity secondary to flaccid paralysis due to polio suffered in childhood. On physical examination, a limitation of the active dorsiflexion of the ankle is observed, first metatarsal in plantarflexion position and a rigid Hallux claw deformity. The equine deformity was reducible. In gait analysis it is appreciated a limitation of ankle dorsiflexion at the initial contact phase with forefoot contact and an increase in knee and hip flexion during oscillation phase. The patient had previously had an elongation surgery of the extensor hallucis longus tendon (EHL). A transfer of the anterior tibial muscle (TA) to the third wedge was performed, Jones tenosuspension with an arthrodesis of the Hallux interphalangeal joint. A lengthening of gastrocnemius was also performed. Twelve months after surgery, the ankle active range of motion was $35^{\circ}$ of plantar flexion and $0^{\circ}$ of dorsiflexion, and the ankle passive range of motion was $15^{\circ}$ of dorsiflexion and $60^{\circ}$ of plantarflexion. The deformity in equine was corrected, also gaining a slight active dorsiflexion of the ankle. The combined tendon transfer of the anterior tibial and the ELP with lengthening of the gastrocnemius as rescue treatment of the equine deformity by a common peroneal nerve neuropathy is a treatment to be taken into account for the correction of this deformity.
\end{abstract}




\section{INTRODUCCIÓN}

La transferencia tendinosa del tibial anterior (TA) a la tercera cuña se puede utilizar para la corrección del pie equino dependiendo del grado de afectación ${ }^{1}$. En algunos pacientes con neuropatía del peroneo común, el músculo que más se afecta es el extensor largo del primer dedo, probablemente debido a una lesión selectiva del fascículo que contiene las fibras motoras que inervan dicho músculo, produciéndose caída del primer dedo² (Tabla I). La transferencia se puede realizar de una forma aislada, o junto a otras, en función de la deformidad que presente el paciente, como por ejemplo la tenosuspensión de Jones para la caída del primer dedo ${ }^{3}$. Otras opciones son la transposición del extensor largo del primer dedo a la tercera cuña, o la transferencia combinada del tibial posterior y anterior a la tercera cuña ${ }^{4}$.

El presente artículo muestra un caso clínico de una deformidad en equino flácido acompañada de limitación a la flexión dorsal de tobillo por retracción de la musculatura posterior, que fue tratado con un procedimiento combinado de resec- ción de gastrocnemios con transposición tendinosa del tibial anterior, extensor largo propio del primer dedo y artrodesis de la articulación interfalángica del primer dedo.

\section{CASO CLÍNICO}

Paciente varón de 52 años de edad, raza blanca, acude a consulta del Centro Clínico Quirúrgico de Aranjuez el 9 de enero de 2018, remitido por otra clínica, habiendo sido diagnosticado de una deformidad en equino por una parálisis flácida secundaria a una poliomielitis que padeció en la infancia, y que afectó de una forma selectiva al fascículo que contiene las fibras motoras y sensitivas de la musculatura anterior del pie derecho. En la exploración física se observó una marcha en equino con limitación para realizar la flexión activa dorsal del pie, con plantarflexión del primer radio flexible (Figura 1). El rango de movimiento activo preoperatorio del tobillo era de $-20^{\circ}$ en flexión dorsal activa, y de $-10^{\circ}$ en flexión dorsal pasiva. En el análisis de la mar-

Tabla I. Inervación sensitiva y motora del Nervio Peroneo Común (Ciático Poplíteo Externo)

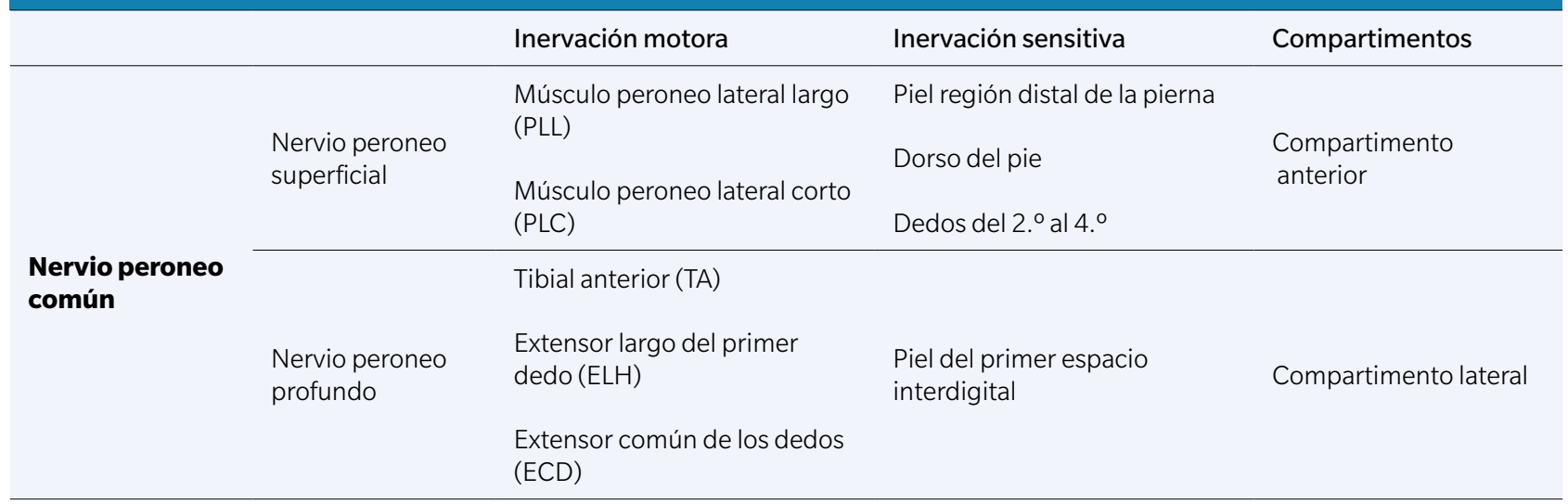

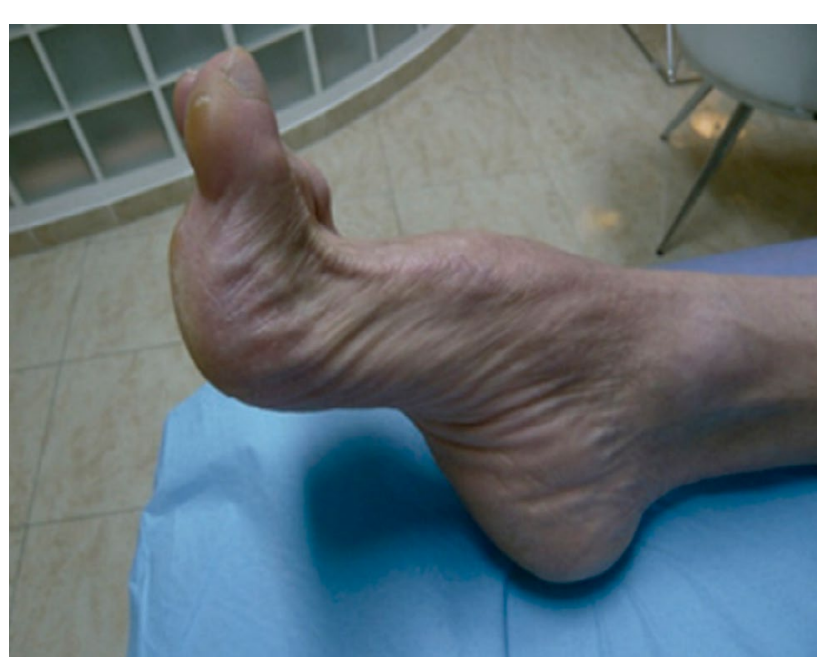

Figura 1. Preoperatorio. cha se apreció una limitación en la flexión dorsal de tobillo en la fase de contacto inicial, con contacto de antepié y un aumento de la flexión de rodilla y cadera en la fase de oscilación; se apreciaba dificultad de la dorsiflexión de tobillo del miembro derecho, con caída del primer metatarsiano, cojera importante y marcha en steppage. La deformidad en equino era reductible. La fuerza muscular, según la escala Medical Research Council ${ }^{5}$ (MRC), fue: 2/5 extensor largo del primer dedo, $3 / 5$ extensor común de los dedos, 5/5 el tibial anterior y el tríceps sural, 2/5 en los músculos peroneos, y el tibial posterior presentaba disfunción con double heel rise test positivo. Los test de Silverskiold y de Lunge eran positivos, con acortamiento de los gastrocnemios. En la exploración neurológica se apreció pérdida de sensibilidad en el primer espacio intermetatarsal, así como en la zona dorsal del pie con disminución de la sensibilidad en los dedos $3 .^{\circ}, 4 .^{\circ}$ y $5 .^{\circ}$. La zona lateral de la pierna normal, pero a partir de la apófisis 


\section{Tabla II. Evaluación clínica}

\begin{tabular}{|c|c|c|c|c|c|}
\hline $\begin{array}{c}\text { Análisis de la } \\
\text { marcha }\end{array}$ & $\begin{array}{l}\text { Fuerza } \\
\text { muscular } \\
(\mathrm{MRC})\end{array}$ & $\begin{array}{l}\text { Exploración } \\
\text { neurológica }\end{array}$ & Otros test & Otras cirugías & $\begin{array}{c}\text { Rango de movimiento } \\
\text { preoperatorio del } \\
\text { tobillo }\end{array}$ \\
\hline $\begin{array}{l}\text { Limitación flexión } \\
\text { dorsal del tobillo } \\
\text { en la fase de } \\
\text { contacto }\end{array}$ & $\begin{array}{l}\text { Extensor largo } \\
\text { del primer dedo } \\
2 / 5\end{array}$ & $\begin{array}{l}\text { Pérdida de } \\
\text { sensibilidad en } \\
\text { el primer espacio } \\
\text { intermetatarsal y } \\
\text { zona dorsal del pie }\end{array}$ & $\begin{array}{l}\text { Silverskiold + } \\
\text { positivo }\end{array}$ & $\begin{array}{l}\text { Alargamiento del } \\
\text { extensor largo del } \\
\text { primer dedo en la } \\
\text { infancia }\end{array}$ & $\begin{array}{l}-20^{\circ} \text { en flexión dorsal } \\
\text { activa }\end{array}$ \\
\hline $\begin{array}{l}\text { Contacto de } \\
\text { antepié y aumento } \\
\text { de la flexión de } \\
\text { rodilla y cadera } \\
\text { en la fase de } \\
\text { oscilación }\end{array}$ & $\begin{array}{l}\text { Extensor común } \\
\text { de los dedos } \\
3 / 5\end{array}$ & $\begin{array}{l}\text { Disminución de la } \\
\text { sensibilidad en los } \\
\text { dedos } 3 .^{\circ}, 4 .^{\circ} \text { y } 5 .^{\circ}\end{array}$ & $\begin{array}{l}\text { Lunge + } \\
\text { positivo }\end{array}$ & & $\begin{array}{l}-10^{\circ} \text { en flexión dorsal } \\
\text { pasiva }\end{array}$ \\
\hline $\begin{array}{l}\text { Dificultad de } \\
\text { la dorsiflexión } \\
\text { de tobillo del } \\
\text { miembro derecho }\end{array}$ & $\begin{array}{l}\text { Tibial anterior } \\
5 / 5\end{array}$ & $\begin{array}{l}\text { Pérdida de } \\
\text { sensibilidad distal a } \\
\text { partir de la apófisis } \\
\text { estiloides }\end{array}$ & $\begin{array}{l}\text { Tibial posterior } \\
\text { double heel rise + } \\
\text { positivo }\end{array}$ & & \\
\hline $\begin{array}{l}\text { Caída del primer } \\
\text { metatarsiano }\end{array}$ & $\begin{array}{l}\text { Tríceps sural } \\
5 / 5\end{array}$ & & & & \\
\hline $\begin{array}{l}\text { Cojera y marcha en } \\
\text { steppage }\end{array}$ & $\begin{array}{l}\text { Peroneo lateral } \\
\text { largo y corto } \\
2 / 5\end{array}$ & & & & \\
\hline
\end{tabular}

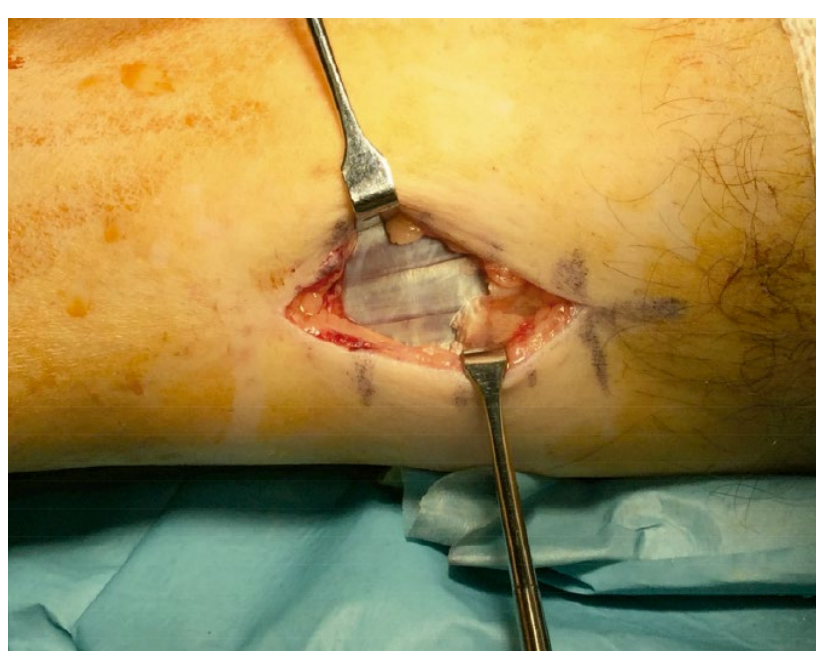

Figura 2. Abordaje de los gastrocnemios.

estiloides, perdía la sensibilidad, refiriendo dolor en el arco longitudinal interno (ALI) y primera articulación metatarsofalángica (1. a AMTF), con un primer dedo en garra rígida. Los pulsos de las arterias pedia y tibial posterior del miembro derecho estaban presentes con buen relleno capilar. El índice T/B en MI derecho fue de 0,90.

En la infancia le realizaron una elongación tendinosa del extensor largo del primer dedo. Presentaba micropodia del miembro derecho con disimetría de un centímetro (Tabla II).
Con fecha 22 de enero de 2018 se realizó la intervención quirúrgica mediante anestesia local con bloqueo poplíteo ( $10 \mathrm{ml}$ de mepivacaína al $2 \%$ mezclado con $10 \mathrm{ml}$ de bupivacaína al 0,5\%) y con hemostasia a través de torniquete neumático por debajo de la rodilla $(200 \mathrm{~mm} \mathrm{Hg}$ ).

Con el paciente en posición lateral derecha se realizó abordaje de los gastrocnemios (Figura 2) para alargar la musculatura posterior, teniendo especial cuidado en no lesionar el nervio sural; en este procedimiento debemos prestar atención en cortar el músculo plantar delgado. Se realizó un segundo abordaje longitudinal desde la 1. a AMTF hasta la articulación interfalángica distal. Desinsertamos el músculo extensor largo del primer dedo de la falange distal para conseguir la mayor cantidad de tendón y poder reinsertarlo en la cabeza del primer metatarsiano. Se realizó una perforación en la cabeza metatarsal de lateral a medial (Figura 3). Se reinsertó el tendón del extensor largo del primer dedo pasándolo por dicho túnel óseo, realizando una dorsiflexión a $0^{\circ}$ para poder fijar a la tensión adecuada (Figura 4), fijando la tenodesis con tornillo reabsorbible. A nivel distal realizamos artrodesis de la articulación interfalángica con fijación de tres agujas Kirschner (Figura 5). A continuación, se realizó un abordaje longitudinal en la cara medial del dorso del pie sobre el tendón del tibial anterior, para desinsertarlo de la base del primer metatarsiano y primera cuña (Figura 6). Mediante otra incisión dorsal a la altura del tobillo se identificó y expuso el tibial anterior para su transferencia. Se sacó el TA por la incisión del tobillo (Figura 7). El extremo distal del TA se preparó 


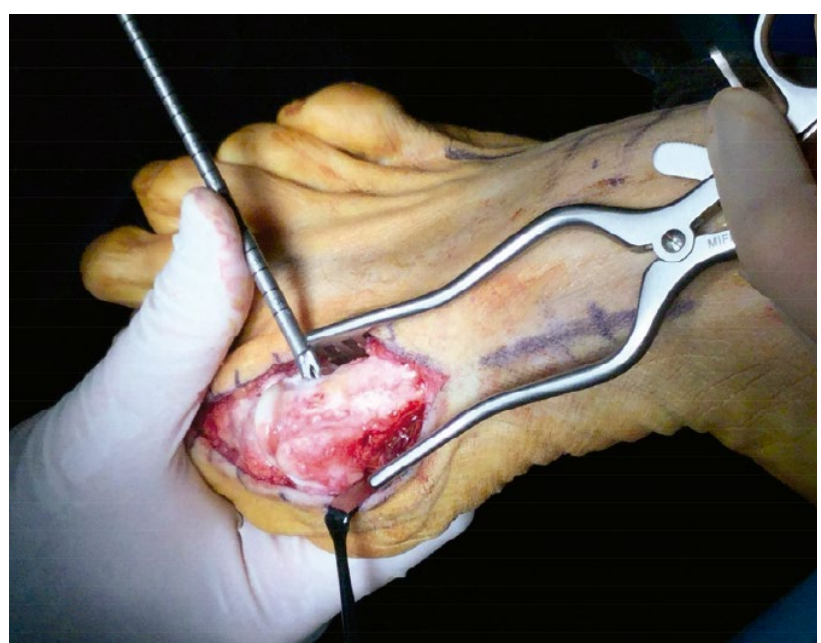

Figura 3. Perforación en la cabeza metatarsal de lateral a medial.

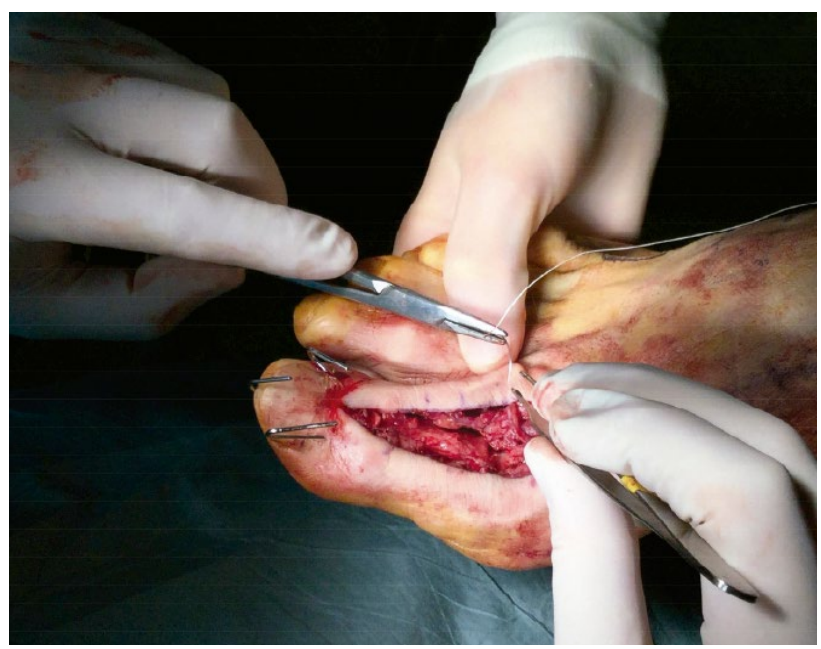

Figura 5. Fijación de la artrodesis 1. a AlFD con tres agujas Kirschner.

con sutura para poder traccionar y reposicionarlo en la tercera cuña. Finalmente realizamos una perforación ósea en la tercera cuña de $5 \mathrm{~mm}$ y se tunelizó la plastia hasta extraer la sutura por la zona plantar (Figura 8). Con el pie a $90^{\circ}$ grados de dorsiflexión se fijó con un tornillo interferencial de biotenodesis biorreabsorbible (Figuras 9 y 10).

El cierre se realizó con técnica subdérmica con poliglecaprone 4/0 y puntos simples de polipropileno 4/0. Se pautó tratamiento postoperatorio con paracetamol de $1000 \mathrm{mg}$ $1 / 8$ horas, ibuprofeno de $600 \mathrm{mg} 1 / 12$ horas y amoxicilina $500 \mathrm{mg} 1 / 8$ horas 8 días.

El pie se inmovilizó con una férula posterior de yeso. En este momento es muy importante el posicionamiento del pie, que debe estar a $90^{\circ}$ hasta la retirada de los puntos a las

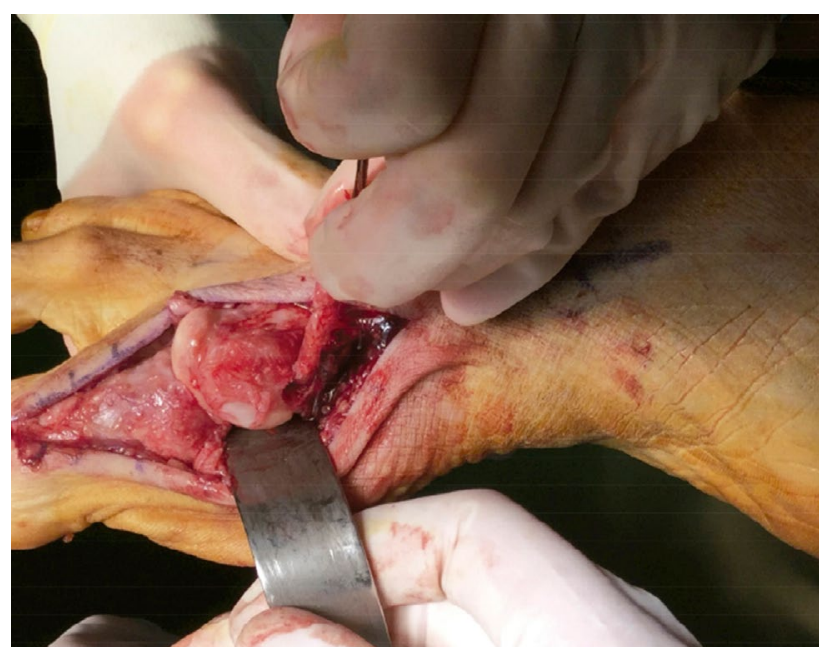

Figura 4. Reinsertamos el tendón del extensor largo del primer dedo pasándolo por dicho túnel óseo, realizando una dorsiflexión a $0^{\circ}$ para poder fijar a la tensión adecuada.

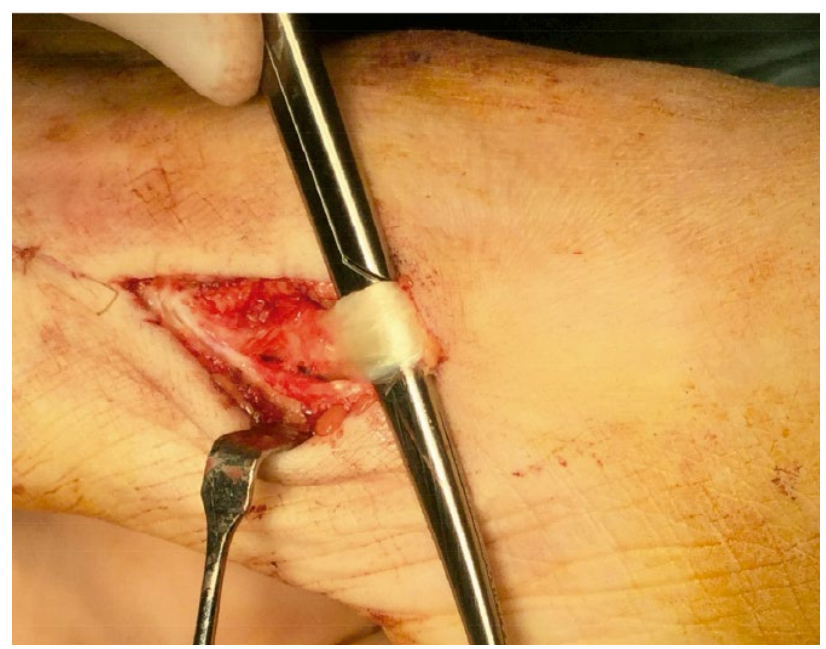

Figura 6. Abordaje longitudinal en la cara medial del dorso del pie sobre el tendón del tibial anterior, para desinsertarlo de la base del primer metatarsiano y primera cuña.

3 semanas; posteriormente se sustituyó por una bota Walker hasta la sexta semana. El pie estuvo en descarga completa hasta la sexta semana, posteriormente se permitió una carga parcial y movilizaciones activas 3-4 veces al día hasta los seis meses.

Doce meses después de la cirugía el paciente no refería dolor y, en el examen clínico, el rango de movimiento activo era de $35^{\circ}$ en flexión plantar y $0^{\circ}$ en flexión dorsal, y el rango de movilidad pasiva dorsal era de $15^{\circ}$ y plantar $60^{\circ}$. Se consiguió la corrección de la deformidad en equino, así como restaurar una mínima dorsiflexión activa del tobillo, suficiente para llevar a cabo una marcha normal. El paciente precisó el uso de una ortesis posquirúrgica con elevación de $7 \mathrm{~mm}$ para compensar su disimetría y así mejorar su biomecánica. 


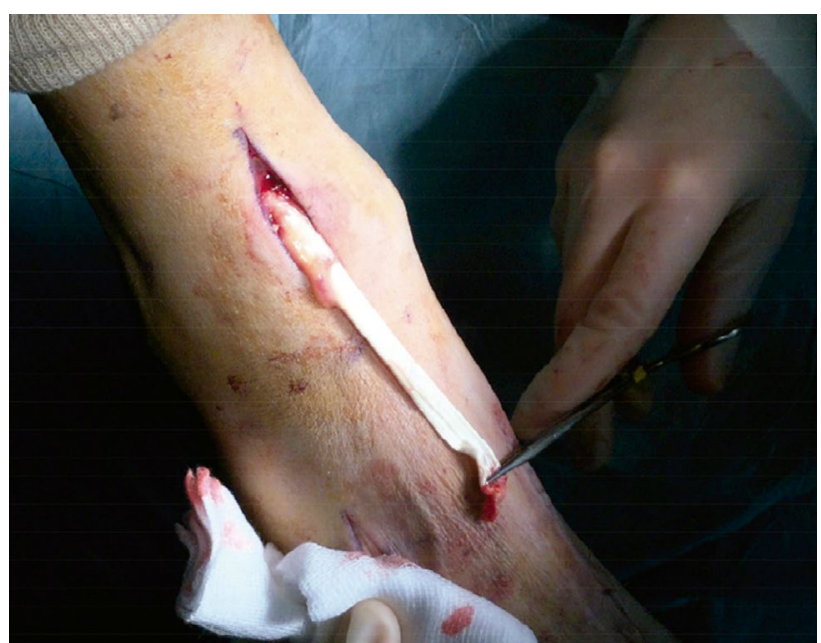

Figura 7. Se extrae el tibial anterior por la incisión del tobillo.

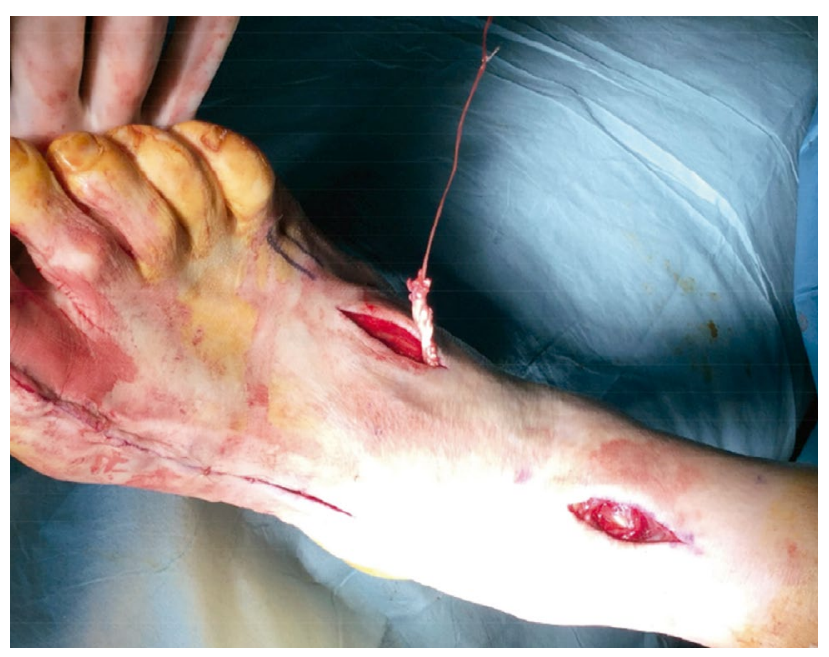

Figura 9. Con el pie a $90^{\circ}$ grados de dorsiflexión se fijó con un tornillo interferencial de biotenodesis biorreabsorbible.

\section{DISCUSIÓN}

El presente artículo muestra un caso clínico de una deformidad en equino secundaria a una parálisis flácida por una poliomielitis que sufrió en la infancia, acompañada de limitación a la flexión dorsal de tobillo por retracción de la musculatura posterior, que fue tratada mediante un procedimiento combinado de resección de gastrocnemios con transposición tendinosa del tibial anterior y extensor largo propio del primer dedo y una artrodesis de la articulación interfalángica del primer dedo.

La cirugía más utilizada para corregir el equino es el alargamiento del tendón de Aquiles, pudiendo realizarse también alargamientos a nivel del gemelo, no estando definido aún qué técnica es más adecuada para cada paciente ${ }^{6-9}$.

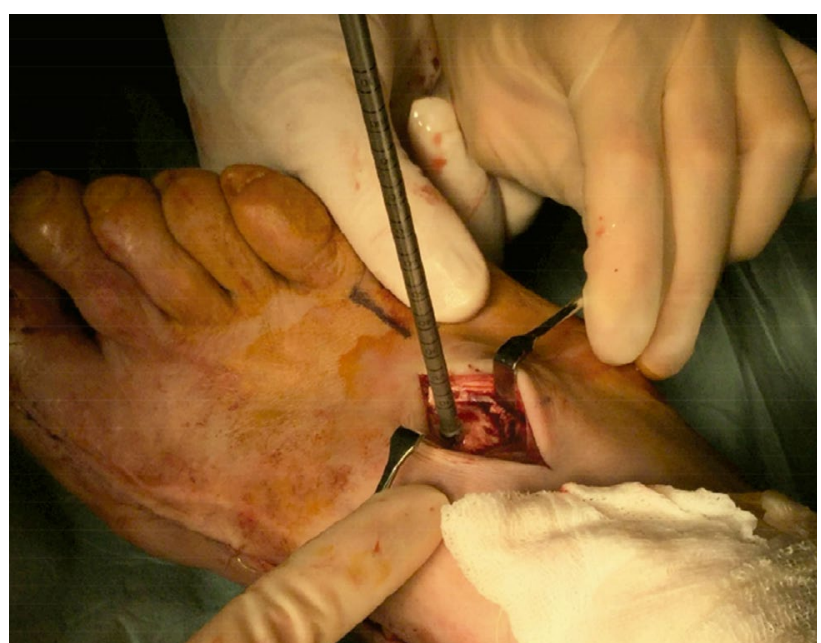

Figura 8. Perforación ósea en la tercera cuña de $5 \mathrm{~mm}$.

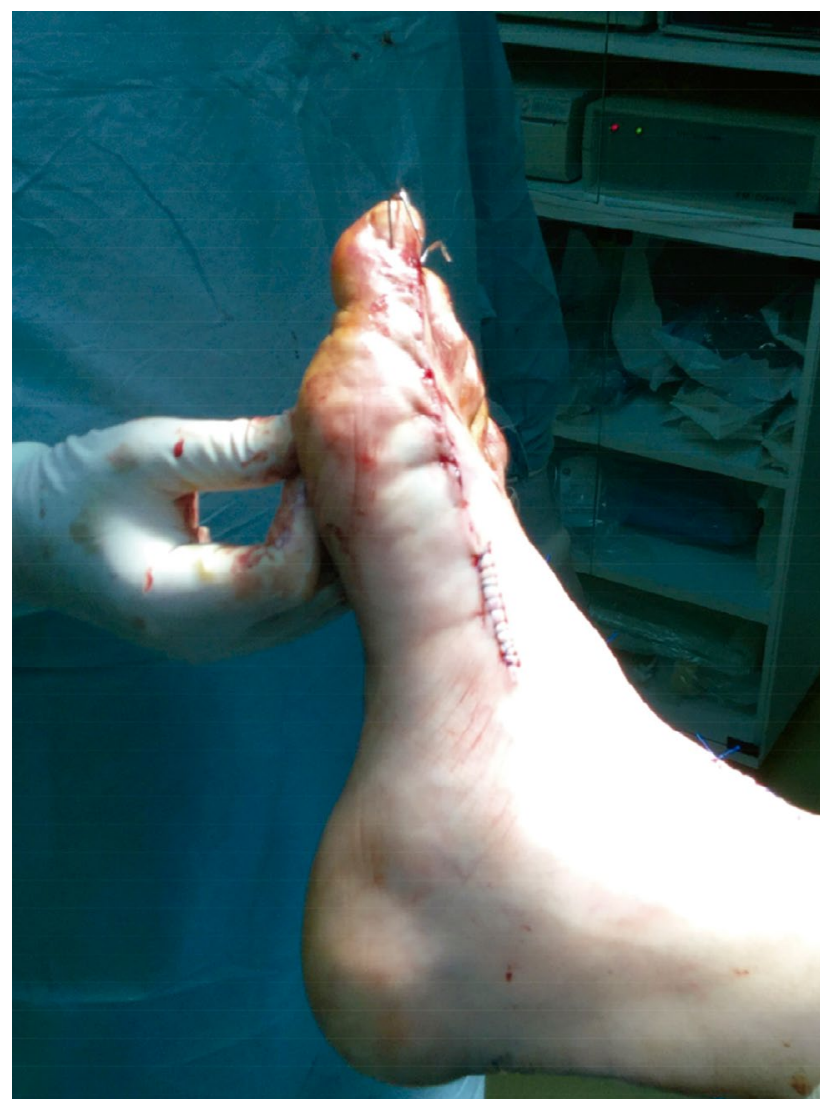

Figura 10. Resultado postquirúrgico.

La recurrencia después de estas cirugías es común y varía entre un 6 y un $54 \%$, dependiendo de factores predisponentes como la edad del paciente, el tipo de parálisis y el tipo de cirugía o el sexo ${ }^{10}$.

La neuropatía del nervio peroneo es la mononeuropatía más común de los miembros inferiores ${ }^{1}$. Al plantear cualquier procedimiento de transferencia tendinosa se deben conside- 
rar los siguientes factores: las fuerzas musculares relativas y la excursión del tendón de cada músculo funcional, sin importar qué tan débil pueda parecer, la posición del tendón relacionada con el resto del pie, la tensión apropiada del tendón transferido, y la fuerza de tracción necesaria para asegurar la transferencia del tendón. Lógicamente debe aproximar la fuerza y recorrido de la unidad motora que está siendo usada para su sustitución, pero este reemplazo equivalente rara vez se logra usando un solo tendón. En consecuencia, es difícil esperar que el extensor largo del primer dedo reemplace al músculo tibial anterior. Tal reemplazo puede ser imposible cuando se hace un intento para compensar la parálisis de los músculos más fuertes, como el tibial anterior o los gastrocnemios, cuando pueden requerirse múltiples transferencias de tendón, todo va a depender de la severidad de la afectación muscular. Es clave dar una adecuada tensión cuando se fija al hueso el tendón trasferido: si el tendón es fijado en un estado relajado, no puede generar la tensión adecuada para traccionar correctamente. Por lo general, es preferible insertar al tendón bajo más tensión que relajación, debido a que siempre hay algo de estiramiento del músculo.

Para solucionar este problema se han descrito diferentes técnicas, como las transferencias tendinosas del tibial posterior $^{11,12}$. En el caso de deformidad en varo o valgo de tobillo concomitante, se deben asociar técnicas correctoras. Rodríguez, en 1992, reportó transferencia del tendón del TP a través de la membrana interósea hacia el dorso del pie con una anastomosis del TA y del peroneo lateral largo por delante del maléolo lateral para restaurar la pérdida de flexión dorsal y equilibrio del pie, evitando una deformidad en varo o valgo secundaria. Los resultados fueron mejores en pacientes con parálisis del nervio peroneo común secundaria a traumatis$\operatorname{mos}^{13}$. Omer, en 1982, ya describió que raras veces se podía conseguir una completa dorsiflexión del tobillo con la transferencia aislada del tibial posterior en el dorso del pie ${ }^{14}$. La unión de la transferencia del TA y la del extensor largo del primer dedo proporciona dorsiflexión y actúa como tenodesis para resistir la flexión plantar hasta que el tendón tibial posterior es reeducado para realizar la flexión dorsal durante la fase de balanceo.

En cuanto al sistema de fijación del tendón sobre el hueso, Nunez Pereira y cols., en 2009, diseñaron un estudio biomecánico para comparar la fijación de transferencia tendinosa del tendón, utilizando anclajes óseos y tornillos interferenciales, llegando a la conclusión que los tornillos interferenciales proporcionan mayor resistencia que los anclajes óseos. El estudio demostró un aumento de la fuerza en la fijación de un hueso in vitro para la transferencia del tendón con tornillos interferenciales, en comparación con los anclajes de sutura ${ }^{15}$. En nuestro caso se prefirió la utilización de tornillos biointerferenciales para realizar la fijación de las transferencias; con esta fijación se evitan las posibles escaras cutáneas que puede ocasionar el botón plantar.

Finalmente, si el tendón se transfiere por debajo del retináculo, el cual funciona como una polea, el rango de movimien- to del tendón se incrementa. Con una posición subcutánea disminuye el recorrido, pero la fuerza motora aumenta debido a la mayor distancia desde los ejes de las articulaciones y el resultado es un brazo de palanca mayor. En general, un tendón es siempre transferido en posición subcutánea, como en el proceso que hemos presentado. En nuestro caso, aun habiendo reinsertado a tensión el extensor largo propio del primer dedo, hubiera sido necesario más tensión para conseguir mayor dorsiflexión del primer radio.

Nuestro objetivo principal de la transferencia tendinosa combinada de tibial anterior, extensor largo del primer dedo y alargamiento de los gastrocnemios era la corrección del pie equino secundario a una parálisis flácida y, con ella, la obtención de una función de tenodesis para mantener la correcta posición del tobillo durante la marcha.

En conclusión, el pie equino secundario a una parálisis flácida debida a una poliomielitis por neuropatía del nervio peroneo común es una entidad que no ha sido diagnosticada de una forma adecuada en el ejercicio clínico habitual. La gran mayoría de los pacientes requieren un tratamiento quirúrgico para corregir la deformidad y conseguir un apoyo plantar correcto, ya que los tratamientos conservadores no son eficaces a medio y largo plazo.

La transferencia tendinosa del TA y el extensor largo del primer dedo con alargamiento de los gastrocnemios, como procedimiento de recuperación del pie equino secundario a una poliomielitis por una neuropatía del nervio peroneo común, es un tratamiento a tener en consideración para la corrección de dicha deformidad. El mayor conocimiento de las ventajas y desventajas de esta técnica nos permitiría que más pacientes pudieran verse favorecidos ante situaciones desfavorables. Son necesarios más estudios para comprobar la eficacia de las diversas técnicas quirúrgicas en los distintos tipos de deformidades, debiendo realizarse un seguimiento a largo plazo de los pacientes, para confirmar su efectividad y resultados.

\section{CONFLICTO DE INTERESES}

Los autores declaran no tener conflicto de intereses.

\section{FINANCIACIÓN}

Ninguna.

\section{BIBLIOGRAFÍA}

1. Pinzur MS. Principles of balancing the foot with tendon transfers. Foot Ankle Clin. 2011;16(3):375-84. DOI: 10.1016/j.fcl.2011.06.001.

2. Stewart JD. Peripheral nerve fascicles: anatomy and clinical relevance. Muscle Nerve. 2003;28(5):525-41

3. Richardson DR, Gause LN. The bridle procedure. Foot Ankle Clin. 2011;16(3):419-33. DOI: 10.1016/j.fcl.2011.06.003.

4. Maas $H$, Baan GC, Huijing PA. Intermuscular interaction via myofascial force transmission: effects of tibialis anterior and extensor hallucis longus length on force transmission from rat extensor digitorum longus muscle. J Biomech. 2001;34(7):927-40. 
5. Medical Research Council of the UK, Aids to the investigation of Peripheral Nerve Injuries, Memorando No.45. London: Pendragon House; 1976. P. 6-7.

6. Galli M, Cimolin V, Santambrogio GC, Crivellini M, Albertini G. Gait analysis before and after gastrocnemius fascia lengthening for spastic equinus foot deformity in a 10-year-old diplegic child. Case Rep Med. 2010:417806. DOI: 10.1155/2010/417806.

7. Vlachou M, Dimitriadis D. Split tendon transfers for the correction of spastic varus foot deformity: a case series study. J Foot Ankle Res. 2010;3:28. DOI: 10.1186/1757-1146-3-28.

8. Craig JJ, Van Vuren J. The importance of gastrocnemius recession in the correction of equinus deformity in cerebral palsy. J Bone Joint Surg Br. 1976;58(1):84-7.

9. Sharrard WJ, Bernstein S. Equinus deformity in cerebral palsy. A comparison between elongation of the tendo calcaneus and gastrocnemius recession. J Bone Joint Surg Br.1972;54(2):272-6.
10. Joo SY, Knowtharapu DN, Rogers KJ, Holmes LJr, Miller F. Recurrence after surgery for equinus foot deformity in children with cerebral palsy: assessment of predisposing factors for recurrence in a long-term follow-up study. J Child Orthop.2011;5(4):289-96. DOI: 10.1007/s11832-011-0352-4.

11. Williams PF. Restoration of muscle balance of the foot by transfer of the tibialis posterior. J Bone Joint Surg Br. 1976;58(2):217-9.

12. Miller GM, Hsu JD, Hoffer MM, Rentfro R. Posterior tibial tendon transfer: a review of the literature and analysis of 74 procedures. J Pediatr Orthop. 1982;2(4):363-70.

13. Rodriguez RP. The Bridle procedure in the treatment of paralysis of the foot. Foot Ankle. 1992;13(2):63-9.

14. Omer GE Jr. Reconstructive procedures for extremities with peripheral nerve defects. Clin Orthop Relat Res. 1982;(163):80-91.

15. Nunez-Pereira S, Pacha-Vicente D, Llusa-Perez M, Nardi-Vilardaga J. Tendon transfer fixation in the foot and ankle: a biomechanical study. Foot Ankle Int 2009;30(12):1207-11. DOI: 10.3113/FAI.2009.1207. 